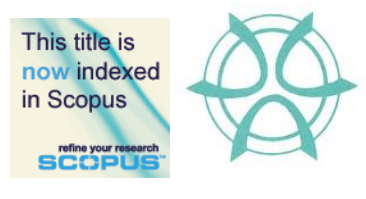

PLANNING MALAYSIA:

Journal of the Malaysian Institute of Planners

VOLUME 16 ISSUE 1 (2018), Page 25 - 37

\title{
EXPERIENTIAL VIRTUAL URBAN ENVIRONMENTS: A PRELIMINARY INVESTIGATION
}

\author{
Izham Ghani ${ }^{1}$, Norhafizah Abdul Rahman², Nadiyanti Mat Nayan ${ }^{3}$, \& Azrul \\ Bahaluddin ${ }^{4}$ \\ ${ }^{1,2,3,4}$ Faculty of Architecture, Planning and Surveying \\ UNIVERSITI TEKNOLOGI MARA
}

\begin{abstract}
Virtual reality (VR) technologies enable users to be virtually immersed in reconstructed cities and streets from around the globe. Immersive technologies could provide users a suggestive sensation of "being there" in a reconstructed virtual urban environments (VUE). This research argues that experiential VUE could promote better understanding of a place while offering unique interactions within its surrounding elements. The aim of this research is to present a preliminary study of the factors determining place experience in a VUE. This research examines two related VUE case studies that offer real-time navigation via a 3D virtual environment (VE) platform to analyse the functionality of the offered interactions and user experience via its contents. Although preliminary investigations have shown some promising results in real-time virtual city walkthroughs, there are still some issues that still need to be addressed in order to provide experiential contents. Based on the findings, this research suggests future VUE improvements focusing on contextual setting, interactivity, navigation, level of details, viewpoints and auditory elements to provide an experiential walkthrough within a VUE. Findings from the case studies would assist and identify specific elements suitable for future development of more meaningful and experiential VUE in the Malaysian context.
\end{abstract}

Keywords: virtual reality, virtual urban environment, experiential, urban design 
Izham Ghani, Norhafizah Abdul Rahman, Nadiyanti Mat Nayan, \& Azrul Bahaluddin

Experiential Virtual Urban Environments: A Preliminary Investigation

\section{INTRODUCTION}

The concept of human experiences towards a particular place have been studied under several terminologies such as place attachment, place identity and place dependence (Jorgensen \& Stedman, 2006). Some argue that these place concepts inherently belong under the same umbrella term, "sense of place" (Cross, 2001; Shamai \& Ilatov, 2005). Although there is an exhaustive literature discussing the complexities in translating and defining people-place association, sense of place commonly describes the unique human experience, bonding and emotion towards a particular place (Ghani, Rafi \& Woods, 2016).

It could be argued that there seems to be a mutual agreement on some of the core aspects of people-place relationship similarly to those concerned with the phenomenological aspects of place relations. Phenomenology in its simplest term is the interpretative study of human experience which could also be defined as the "exploration and description of phenomena, where phenomena refers to things or experiences as human beings experience them" (Seamon, 2000). Phenomenology is also concerned with "the study of experience from the perspective of the individual, 'bracketing' taken-for-granted assumptions and usual ways of perceiving" (Lester, 1999). Norberg-Schulz (1984) has highlighted the need for a phenomenological approach in architecture to safeguard the spirit of place or the genius loci, to avoid the loss of place.

In the context of a virtual environment (VE), studies in sense of place are arguably related to the studies of presence (Ghani et al., 2016). Presence or telepresence is commonly defined as a user's subjective sensation of "being there" (Lessiter, Freeman, Keogh, \& Davidoff, 2001) and known to be a fundamental concept for understanding and evaluating the effectiveness of virtual environments (MacIntyre, Bolter, \& Gandy, 2004). This is a vital concept in defining virtual reality in the context of human experiences rather than focusing on its technological hardware (Steuer, 1992). The term presence itself has been used in a wide range of research areas hence expanding its definition, albeit making the concept even harder to define (Meehan, Insko, Whitton, \& Brooks Jr., 2001).

This article will initially discuss the theoretical foundation of place experience in an urban setting based on three factors; physical setting, activities and meanings. Then, two case studies of related VUE projects will be reviewed using a qualitative review method that focuses on the structure of the VUE that was used to represent and visualize the city's environment. The elements selected for the review were extracted from studies in VE design, virtual place and presence, and game-style interactions. Finally, based on the literature review and case study findings, this research will discuss the importance of six elements namely: contextual setting, interactivity, navigation, level of details, viewpoints and auditory elements in providing an experiential walkthrough within the VUE. 


\section{SENSE OF PLACE IN URBAN SETTING}

It could be argued that experiential VUE could promote better understanding of a place while offering unique interactions within its surrounding elements. Elements that were considered in developing place experience are adapted from the theories of perceptual dimension adopted by Carmona, Heath, Oc and Tiesdel (2010), in which it signifies the importance of physical setting, activity and meaning (Figure 1). Sense of place in urban setting could be defined as the qualities that contribute to making each place unique and distinctive. The main qualities that contribute to sense of place are its physical and functional characteristics that relate to the human activities, which in turn, impart meanings to a place.

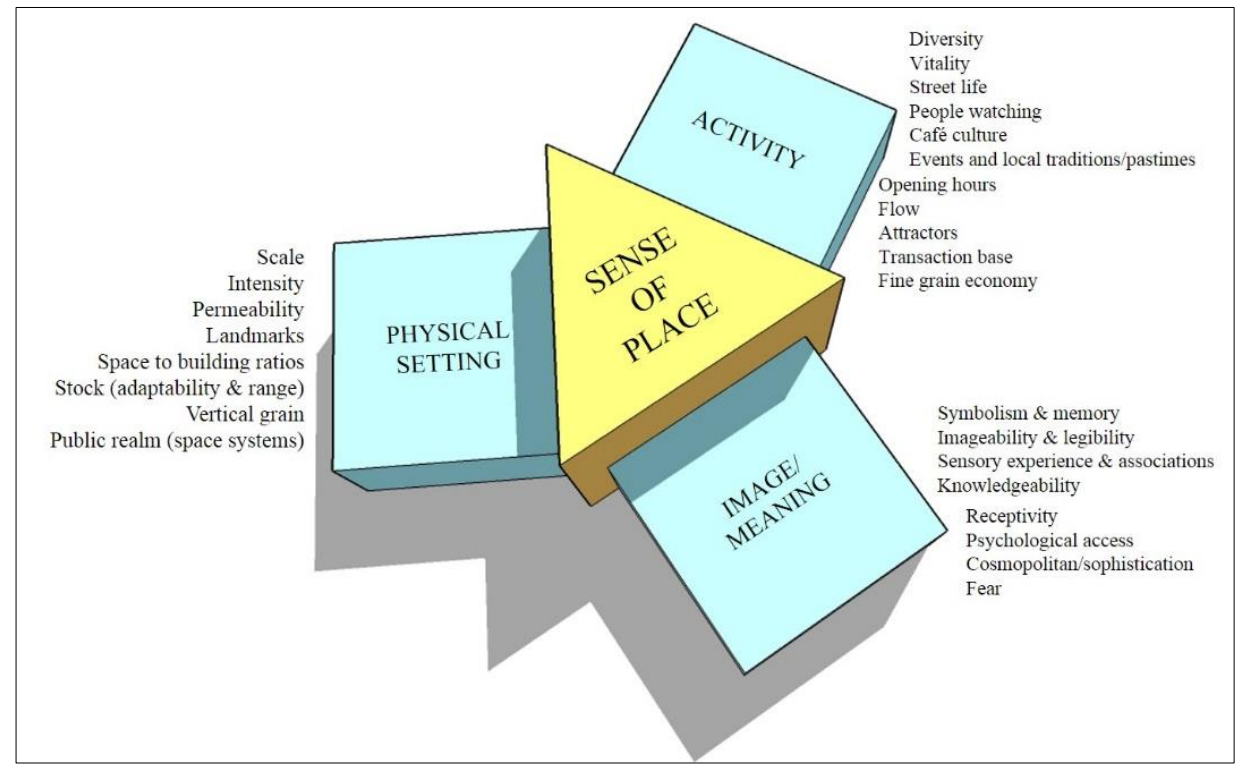

Figure 1: Sense of place dimension

Source: Montgomery, 1998 cited in Carmona et al., 2010

\section{Physical Setting}

Physical setting in built environment generally consist of building edges, streets, paths, squares and other outdoor spaces. The relationship between human and their surroundings; setting and space; is distinctive as it is relying on the individual experience including his perception and senses (Wolfe, 2016). Hence, the characteristic of the urban setting in a different context represents different meaning as it depends on how human observe, sense and interpret their surroundings. Spaces and settings will possibly evoke different feelings; either optimistic or undesirable (Nayan, 2016a, 2016b). Jacobs (1961) highlights the importance of the interaction between human and his experience in an urban 
Izham Ghani, Norhafizah Abdul Rahman, Nadiyanti Mat Nayan, \& Azrul Bahaluddin

Experiential Virtual Urban Environments: A Preliminary Investigation

space. “...please look closely to real cities. While you are looking, you might as well listen, linger and think closely about what you see" (Jacobs, 1961). Lawson (2001) also highlights the importance of setting which constitutes the elements of space, surrounding and contents, as well as the people and their activities.

Each space represents the originality of the city; either through its unique history or distinctive built forms (Nayan, 2010; Nayan \& Jones, 2011). The experience is closely depends on the "arrangement of the elements of the urban setting" (Debord, 1955). The path, the streets, the ambience between the building and the transition within a space are among the features that repealed the unique character of a space. The characteristic of an urban setting embodies through a mixture between newer and older built structures (Nayan \& Jones, 2011). It is full with different architectural style, decorations and colours which become an 'image map' for the observer. Though, the experience gained is remained very subjective to the observer and it is not solely depends on the characteristic of the physical elements itself (Debord, 1955; Thomas, 2016). The experience in urban setting are abstract and contributed by complexities of the urban characteristics and related to the performance of the urban space components (Thomas, 2016).

\section{Activities}

Activities in urban places create a sense of life and vitality (Rahman, Sakip, \& Nayan, 2016). Good qualities of physical setting will increase the optional and social activities in urban places (Rahman, Ghani, Bahaluddin, \& Hussain, 2017). Social activities are influenced by the users' attributes such as age, past experiences, emotional conditions, and others. Furthermore, Mehta (2013) adds that characteristics of the setting in terms of its location, access, conditions, and sensory qualities also influenced those activities. Social activities in urban open spaces have been used as a measure of the town's vitality and liveliness and as an indicator of the satisfaction of people with their physical surroundings (Mehta, 2007).

Much can be learnt about the culture of a society of a place from the activities and how the place is used (Shamsuddin \& Sulaiman, 2010). According to Rahman, Shamsuddin and Ghani (2015), the physical setting of a place either supports or inhibits the use of urban places as a setting for the activities in urban area. Through experiential elements in urban setting, the relationship between people and place setting can be determined; the varieties of personal, social and cultural actors; and physical and functional characteristics of the urban environment that influence people's activities and behavioural in place setting (Thwaites \& Simkins, 2007). Jackson (as cited in Carmona et al., 2003) argues that activities and meanings are the more significant elements as compared to the physicality of places in creating sense of place. 
PLANNING MALAYSIA

Journal of the Malaysia Institute of Planners (2018)

\section{Meanings}

The meaning of place and sense of place are composed of something more than physical and material. It is how and why people use and interact with their spaces that creates unique and meaningful places. Our sense of being in our local culture has significant effects on our place experience, and how we perceive our surroundings in the physical environment. Augustin (2009) signifies the importance of cultural differences in place design as people from different cultures and origins would respond to the same physical environment in "very different ways." This situation occurs due to their familiarity with their urban settings. Sense of familiarity and belonging to a place are associated with people, place setting and activities (Mehta, 2007).

Meaning of place is created and valued differently by different group of users through their personal experiences and values in urban places. Perception is an important factor in people-place relationships (Lavoie, 2005; Lengen \& Kistemann, 2012). Perception is defined as "the act of using only one's own sense organs to gain knowledge about, interact with and experience the environment" (Boothe, 2002). According to Rapoport (1977), perceptual components are the ways in which individuals experience the world, which is a principal mechanism linking people and environment.

\section{METHODOLOGY}

This research adopted a qualitative review and analysis method for each of the case study. Findings from these case studies helped to identify specific elements suitable for future development of VUE contents in the Malaysian context. Relevant issues and limitations of currently published VUE were also identified to support future developmental phase. The case studies were selected from various publically accessible projects consisting of 3D representations of cities and streetscape from around the globe.

The two case studies selected offers real-time navigation via a 3D VE platform, namely: Virtual Old Prague and Barcelona in Gothic. Both VUE projects were developed from two different platforms; Virtual Reality Modeling Language (VRML) for Virtual Old Prague, and game engine for the iOS based Barcelona in Gothic mobile application.

The aim of the case studies was to analyse and compare the relevant methods from published VUE projects to seek the practicality and functionality of the offered interactions and user experience via its contents. The investigation of the VUE projects was evaluated through direct observation method by the authors. A standardised testing setup was used to avoid irregularity and bias to gain uniformity in all of the case study evaluations. The hardware used for the evaluation of the web-based VUE application was a 15.6" Windows 8.1 64-bit gaming laptop equipped with NVidia GeForce GTX 765M graphic card, and the 
Izham Ghani, Norhafizah Abdul Rahman, Nadiyanti Mat Nayan, \& Azrul Bahaluddin

Experiential Virtual Urban Environments: A Preliminary Investigation

mobile application was reviewed via an iPad 3 Mini with iOS 8.1.2 installed. Over-the-ear stereo headphones were used for audio review of the VUE contents.

Research on comparative case studies of VUE related projects focusing on user interactions and place experience is still not widespread, which proved to be a challenge in conducting the evaluation. Nevertheless, using direct observation method, the qualitative review focuses on the structure and contents of the VUE that was used to represent and visualize the city's environment.

\section{VIRTUAL URBAN ENVIRONMENT CASE STUDIES}

\section{Virtual Old Prague, Czech Republic}

The Virtual Old Prague (VOP) project is a web-based virtual tour application, which allows users to navigate through a virtual city stored in a remote database. To enter the site, users are required to install the recommended Cortona VRML Browser from the project's website. The VOP project can be considered to be the first 3D city from the central European region published on the internet.

The VOP website offers 24 virtual locations around the city of Prague which could be customised in the configuration page. The city model only provides the view of the exterior environment that consists of building façade, trees and street furniture such as street lamps and street signage. Users are able to navigate the site while referring to the text information supported with photographs and illustrations of the place elements. Navigation is straight forward in which the users could walk or fly freely throughout the uninhabited virtual cityscape. The main navigation screen is divided into two main sections, which consist of the 3D VRML navigation window (left), and a static section displaying various information on the history and details of the selected locations or buildings (Figure 2). Inside the VE users could click on objects to be redirected to the city's informative website such as Transport Company of Prague from "Little Quarter Square I" environment. Guided tours could also be selected from the main menu. 


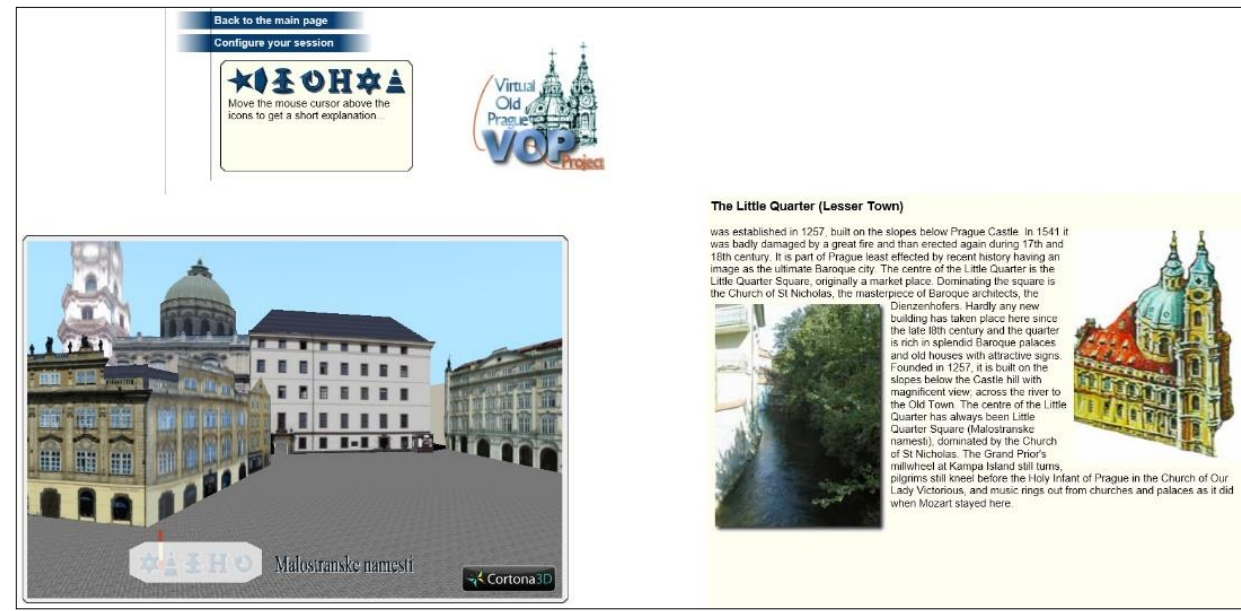

Figure 2: Layout arrangement of the main navigation interface

The interactive section is found in the starting menu that includes the option to customise the level of details (LOD) of the navigation window as well as other VRML setting such as weather, day or night selection. The LOD could be set to the highest setting for better graphics quality but not as rich as those in the more current version of 3D web plugins such as OSG4Web. The navigation offered a first-person perspective viewpoint and could be adjusted to a taller viewing height from the "Avatar size" option. An aerial view of the city could be observed when selecting the flying mode.

However, there is no auditory element in the virtual walkthrough and no auditory-related option available in the configuration page. One of the main issues in VOP is perhaps the incompatibility of certain browsers to load VRML settings which causes some lagging, slow loading of the navigation window or failure to load the application. This is perhaps due to the incompatibility of the older settings in the VRML walkthrough compared to the present setup of the testing platform. This in a way affected users' attempts to experience the interesting place elements as described in the information section. Place elements and cues such as "music rings out from churches" or the "magnificent view across the river to the Old Town" as noted in the supported texts were not translated into the VRML model. Maybe further improvements such as ambience sounds, dynamic elements such as wind effect or avatars could capture some of the interesting heritage elements of the Old Prague townscape.

\section{Barcelona in Gothic, Spain}

The project was developed as a mobile application specifically for the iPad in 2011 as stated on the project's web page (http://www.barcelonamedia.org): 
Izham Ghani, Norhafizah Abdul Rahman, Nadiyanti Mat Nayan, \& Azrul Bahaluddin

Experiential Virtual Urban Environments: A Preliminary Investigation

"Developed originally with the consulting of the Museum of History of Barcelona about the platform of three-dimensional visualization of Barcelona Media, the project 'Barcelona in Gothic' combines the technology of video games to access contents of high visual quality, integrating historical information contrasted with experts and introducing the temporary factor in a very visual manner to represent the evolution of singular elements of the city from the 11th century to the present day".

The VUE sets itself in the middle of a city centre surrounded by a mixture of contemporary buildings and heritage monuments in Barcelona's Gothic Quarter (Figure 3). The city's distinguished landmark is the Barcelona Cathedral which is recognisable from a distance. The city's landscape gives a strong visual image of the city's heritage quarter but lacks any auditory elements.

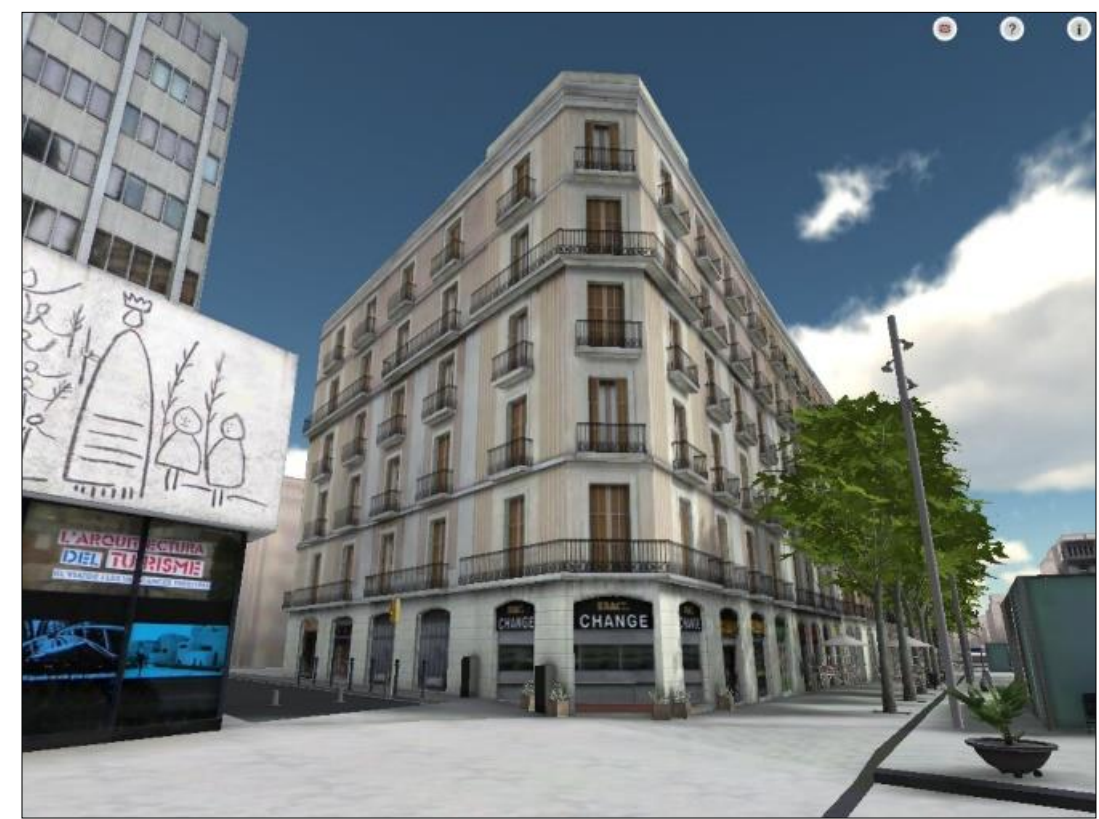

Figure 3: Some of the buildings encountered in the city

The navigational functions use the similar walk and view touch zones as found in most mobile gaming application. Users are able to walk freely through the city's wide walkway and observe the highly detailed building facades. The navigation only allows navigation along the exteriors of the buildings, as there is no option to enter the interior. Users are offered information on specific heritage buildings (Gothic elements) through the interactive "information points" which needs to be clicked to trigger the pop-up information texts. 
PLANNING MALAYSIA

Journal of the Malaysia Institute of Planners (2018)

As noted on the project's website, the VUE uses video games technology to produce high-quality graphics and informative visual contents. The details could be observed throughout the navigation in which the 3D buildings were mapped with high-resolution textures to create an authentic look. The VUE offers first-person perspective viewpoints and are scaled approximately at human's eye level. However, there is no auditory element present in the VUE.

The Barcelona's Gothic Quarter project offers a rich visual experience on the city's architectural heritage. It combines the present and the past historical contents with interactive functions for the users. The only missing element is the auditory support which could enhance the place experience further.

\section{RESULTS AND DISCUSSION}

Based on the case study analyses and findings, it could be argued that supporting elements such as contextual setting, interactivity, navigation, level of details, viewpoints and auditory are necessary to provide an experiential VUE. This is supported by similar studies by Bostan (2009) and, Bostan and Ogut (2011), whom studied the design requirements for $\mathrm{VE}$ and their effects on virtual presence via computer role-playing games. The findings of the requirements and elements for virtual presence in computer games by those authors are found to be relevant to the evaluation of the case studies of this research.

\section{Contextual Setting}

It was observed that both of the case studies provide unique real-time explorations through the VUE which was specifically designed to accommodate the respected project's objectives. Both projects focused on replication of selected exterior environment, which provides a comprehensive large-scaled environment for exploration through some of the city portions. However, the physical environment in the VUE provided only a visual glimpse of the urban setting and failed to deliver a notion of sense of place due to the lack of "living" entities and activities that could be portrayed by animated avatars.

\section{Interactivity}

Both projects offer some forms of interactivity within their contents. The interactive contents are mostly unique to suit each of the respected projects' objective. Virtual Old Prague provide interactive customisation functions such as weather modification, day or night selection, and others. Barcelona in Gothic provide users with clickable interactive information points at various locations in the city. Some of the other issues identified from the case studies were the lack of auditory elements and interactive avatars to provide interactive contents. Ambient sounds and interactive avatars could provide the extra liveliness factor in the VUE especially for contents that represent urban places with cultural heritage importance. 
Izham Ghani, Norhafizah Abdul Rahman, Nadiyanti Mat Nayan, \& Azrul Bahaluddin

Experiential Virtual Urban Environments: A Preliminary Investigation

\section{Navigation}

Real-time navigation is offered by all projects reviewed, which could be considered as a standard practice for most architectural walkthrough. As most of the projects reviewed were developed using game engine technology, game-style navigation using mouse and keyboard were commonly used for navigational controls. For mobile-based applications, navigation is possible through "walk and view" touch zones similar to those in mobile gaming applications. While most projects offer the walking mode as the default navigation technique, some projects such as Virtual Old Prague include the option for flying through the environment. The different navigational techniques provide users with several options for exploring the VUE. Flying mode might provide an easier and faster navigation option especially when exploring large scaled VUE such as cities or districts. However, flying might deter the sensation of place experience due to its dissimilarity to the users' real-world navigation experience. Experiencing architectural heritage and buildings in a VUE may require human eye level observation as originally intended by the architects who designed them. For sense of place to be experienced, replicating real life movement and navigation in the VUE might be a considerable option.

\section{Level of details}

The types of platform for development and dissemination of the VUE contents generally correlate to the type of LOD for most of the projects. Game engine technology such as in Barcelona in Gothic provides sufficient visual realism when compared to older VRML graphics such as observed in the Virtual Old Prague project.

\section{Viewpoints}

All projects and applications offer a first-person perspective viewpoint as their default starting position. Game engine based VUE has been found to be similar to that of a first-person RPG game environment, where users are able to observe their surroundings while walking through some of the reconstructed places. In a web-based 3D VUE such as in Virtual Old Prague, viewpoint modifications could be made prior to entering the environment. The avatar size could be increased for a wider view of the surroundings although it might reduce the feeling of realistic walking and perhaps disconnecting the essence of the intended place. 


\section{Auditory}

Auditory elements could be considered as one of the important components in VUE contents especially those that intend to simulate real places and ambience. Surprisingly, both projects do not include any auditory elements in their VUE considering the visual richness of their contents.

\section{CONCLUSION}

Preliminary findings from the case studies have provided some insights on the current trends in VUE contents particularly those that offer real-time walkthrough experience. Designing place elements in VUE require a collective development strategy to provide the user with meaningful content and interaction while immersing in the reconstructed environment (Figure 4). As previously mentioned in the introduction section, studies in sense of place is arguably related to the studies of virtual presence within the context of VEs. The importance of physical setting, activities and meanings in the real environment could be simulated through the elements of contextual setting, interactivity, navigation, level of details, viewpoints and auditory.

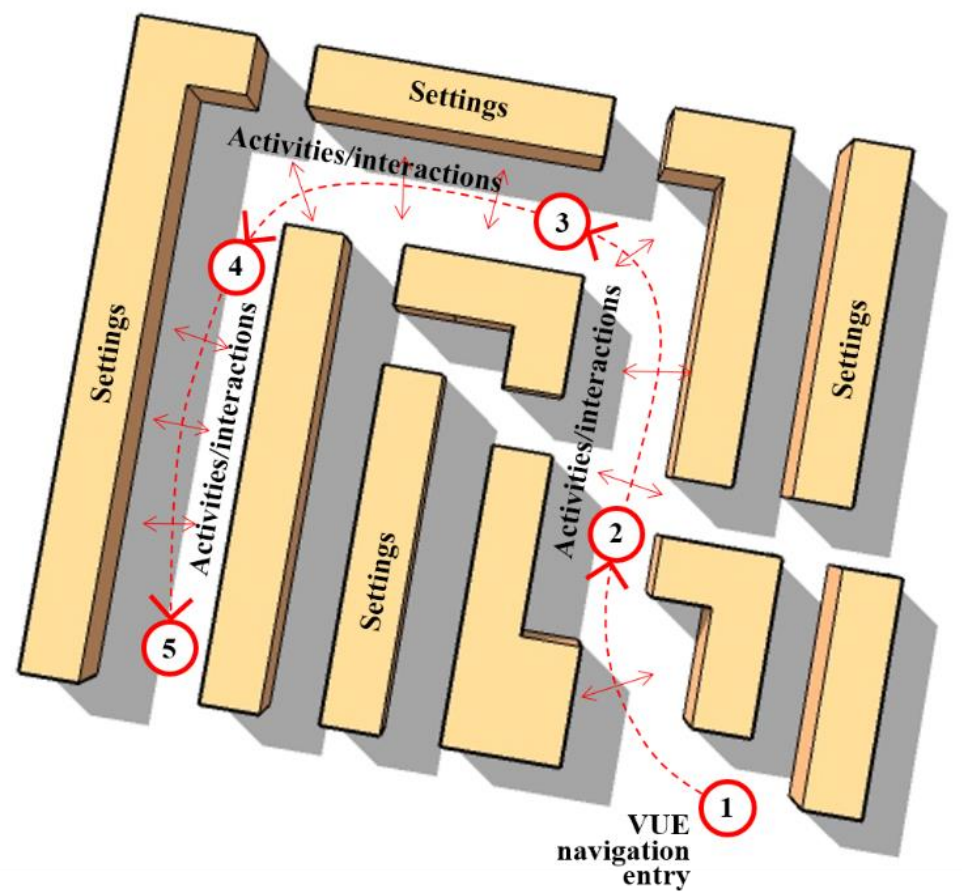

Figure 4: Proposed development strategy for an experiential VUE 
Izham Ghani, Norhafizah Abdul Rahman, Nadiyanti Mat Nayan, \& Azrul Bahaluddin

Experiential Virtual Urban Environments: A Preliminary Investigation

Specific consideration should be given from the beginning of the VUE development process to the dissemination of contents to the end user. Aspects to consider include the selection of visualisation platform, dissemination method, interpretative and personalisation features. Further improvements on the development of the experiential contents is vital to suit the current VR hardware for an enhanced virtual urban place experience.

\section{REFERENCES}

Augustin, S. (2009). Place advantage: Applied psychology for interior architecture. Canada: John Wiley \& Sons, Inc.

Bostan, B. (2009). Requirements analysis of presence: Insights from a RPG game Computers in Entertainment (CIE), 7(1), 1-17.

Bostan, B., \& Ogut, S. (2011). Presence in computer games: Design requirements. Paper presented at the GAMEON'2011, National University of Ireland, Galway, Ireland.

Carmona, M., Heath, T., Oc, T., \& Tiesdell, S. (2003). Public places, urban spaces: The dimensions of urban design. London: Architectural Press.

Carmona, M., Heath, T., Oc, T., \& Tiesdell, S. (2010). Public places, urban spaces: The dimensions of urban design (2nd ed.). London: Architectural Press.

Cross, J. E. (2001). What is sense of place? [Online]. Available: http://www.western.edu/headwaters/archivesheadwaters12_papers/cross_paper .html [2017, June 15].

Debord, G. (1955). Introduction to a critique of urban geography. Les Lèvres Nues, 6.

Ghani, I., Rafi, A., \& Woods, P. (2016). Sense of place in immersive architectural virtual heritage environment Proceedings of the 22nd International Conference on Virtual System \& Multimedia (VSMM) 2016 (pp. 1-8). Kuala Lumpur, Malaysia: IEEE.

Jacobs, J. (1961). The death and life of Great American Cities. New York: Random House Inc.

Jorgensen, B. S., \& Stedman, R. C. (2006). A comparative analysis of predictors of sense of place dimensions: Attachment to, dependence on, and identification with lakeshore properties. Journal of Environmental Management, 79(3), 316-327.

Lavoie, C. (2005). Sketching the landscape: Exploring a sense of place. Landscape Journal, 24(1), 13-31.

Lawson, B. (2001). The language of space. Oxford: Architectural Press.

Lengen, C., \& Kistemann, T. (2012). Sense of place and place identity: Review of neuroscientific evidence. Health \& Place, 18(5), 1162-1171.

Lessiter, J., Freeman, J., Keogh, E., \& Davidoff, J. (2001). A cross-media presence questionnaire: The ITC-Sense of Presence Inventory. Presence: Teleoperators and Virtual Environments, 10(3), 282-297.

Lester, S. (1999). An introduction to phenomenological research. [Online]. Available: www.sld.demon.co.uk/resmethy.pdf.

Mehta, V. (2007). Lively streets: Determining environmental characteristics to support social behavior. Journal of Planning Education and Research, 27(2), 165-187.

Mehta, V. (2013). The street: A quintessential social public space. Oxon, UK: Routledge. 
Nayan, N. M. (2010). Conserving the heritage spaces of Kuala Lumpur: A case study of the Old Market Square (Medan Pasar). Paper presented at the International Conference on Preservation and Promotion of Heritage, Penang, Malaysia.

Nayan, N. M. (2016a). Reviving Sydney Lake as the Historical Park of Kuala Lumpur. Procedia - Social and Behavioral Sciences, 222 (23 June 2016), 578-586.

Nayan, N. M. (2016b). Sydney Lake: The historical park of KL. Asian Journal of Environment-Behaviour Studies, 7(27).

Nayan, N. M., \& Jones, D. (2011). Conserving the heritage spaces of Kuala Lumpur: A case study of the Old Market Square (Medan Pasar). In S. Mohd, A. Azman, J. Sulaiman, \& J. L. Fernandez (Eds.), Multifaceted Aspects of Asian Heritage. Penang, Malaysia: School of Social Sciences, Universiti Sains Malaysia (USM).

Norberg-Schulz, C. (1984). Genius loci: Towards a phenomenology of architecture. New York: Rizzoli.

Rahman, N. A., Ghani, I., Bahaluddin, A., \& Hussain, N. H. (2017). The need for good social behavior through people friendly urban streets. Environment-Behaviour Proceedings Journal, 2(5), 469-477.

Rahman, N. A., Sakip, S. R. M., \& Nayan, N. M. (2016). Physical qualities and activities for a user-friendly shopping street in the context of a Malaysian city. Procedia Social and Behavioral Sciences, 222, 196-202.

Rahman, N. A., Shamsuddin, S., \& Ghani, I. (2015). What makes people use the street?: Towards a liveable urban environment in Kuala Lumpur city centre. Procedia Social and Behavioral Sciences, 170, 624-632.

Rapoport, A. (1977). Human aspects of urban form: Towards a man-environment approach to urban form and design. Oxford, England: Pergamon Press.

Seamon, D. (2000). A way of seeing people and place: Phenomenology in environmentbehavior research. In S. Wapner, J. Demick, T. Yamamoto, \& H. Minami (Eds.), Theoretical perspectives in environment-behavior research (pp. 157-178). New York: Plenum.

Shamai, S., \& Ilatov, Z. (2005). Measuring sense of place: Methodological aspects. Tijdschrift voor economische en sociale geografie, 96(5), 467-476.

Shamsuddin, S., \& Sulaiman, A. B. (2010). The street and its influence on the sense of place of Malaysian cities. In H. C. Kiang, L. B. Liang, \& H. Limin (Eds.), On Asian streets and public space: Selected essays from Great Asian Streets Symposiums (GASS) $1 \& 2$. Singapore: Ridge Books.

Thomas, D. (2016). Placemaking: An urban design methodology. New York: Routledge.

Thwaites, K., \& Simkins, I. (2007). Experiential landscape: An approach to people, place and space. Oxon: Routledge.

Wolfe, C. R. (2016). Seeing the better city: How to explore, observe, and improve urban space. Washington: Island Press. 